\title{
A Suggestion of an Efficient Communication Method of Automobile Internet Banner Advertisements
}

\author{
Sang-Jin Park \\ Department of Visual Design \\ Konyang University, Nonsan, 320-711, Korea
}

\begin{abstract}
Internet banner advertisement has become recognized as an important media, and its influence has been increasing. The merits of Internet banner advertisement are diversity and consumer immersion. Especially, by using various types and visual expression methods, the automobile Internet banner advertisement has evolved into what attracts curiosity and interest of potential consumers. Thus, to find efficient communication method for automobile Internet banner advertisement, this study, by comprehensively analyzing various advertisement methods in previous researches, suggested an advertisement type and a visual expression method suitable to automobile Internet banner advertisement. Four types of automobile Internet banner advertisement are production form, production purpose, expression form, and advertisement area. Four visual expression methods are action form, image, change form, and moving form. And, through case analysis, this study also examined the value of the newly suggested method.
\end{abstract}

Key words: Automobile, Internet Banner Advertisement, Advertisement Type, Visual Expression.

\section{PREFACE}

According to specialists of the Korea Internet Marketing Association, the volume of the Internet marketing market would be 1 trillion 500 billion won. It means that, as the size of Internet advertisement market has grown rapidly online advertisement medium has been recognized as an important advertisement medium. The final purpose of Internet advertisement is to attract consumers to buy the products, and what is needed here is creative strategy. Creative strategy in Internet advertisement can make a lifeless product a living thing, and creative and influential idea can move minds of consumers [1]. The core of such a creative strategy can be said to be efficient communication. Advertisement is communication medium where the company meets consumers for the final time, and it is the most efficient means by which the company can attract demands of consumers. On the other hand, with the diversification of advertisement media, creative strategy itself needs to be differentiated depending on each medium [2]. As part of differentiation strategy, recent Internet banner advertisements, to attract more consumers to participate in those advertisements, frequently provide exciting impacts or add game functions, leading consumers to be immersed in them [3]. The FCB (Foote, Cone \& Belding) Grid model describes procurement behavior of consumers by two dimensions: involvement and reason(think)/emotion(feel). Automobile

* Corresponding author,Email: sjp@konyang.ac.kr Manuscript received Nov. 19, 2013; revised Nov. 12, 2013; accepted Nov. 21, 2013 banner advertisement belongs to the high involvement-think group. This group is characterized by need of information, and it understands consumers as rational beings. It is viewed that consumers, in making procurement decision of a product, consider function, price, and usefulness of it [4]. Consequently, it is necessary to develop the automobile banner advertisement type and visual expression method which reflect the characteristics of high involvement-think group.

This study, for efficient communication method of automobile banner advertisements, wanted to collect and analyze previous researches related with Internet banner advertisements, and suggested automobile banner advertisement types and visual expression methods which comprehensively summarize the characteristics of automobiles. And, to identify the values of suggested banner advertisement types and visual expression method, this study performed case analysis. The findings of such analysis are expected to be helpful in establishing efficient communication strategies in automobile Internet banner advertisements.

\section{PREVIOUS RESEARCHES}

\subsection{Banner advertisement types}

In the process of forming attitude on banner advertisement, consumers go through the sensing and understand it [5]. Researchers have classified types of banner advertisement which play important roles for customers to form such attitudes in various ways. Yu-gyeong $\operatorname{Ko}(2011)$ classified banner advertisement types depending on exposed types. As shown in Table 1, this study classifies types of banner advertisement into 
four types: production form, posting method, expression method, advertisement scope [6].

Table 1. Classification of banner advertisements depending on exposed types

\begin{tabular}{l|l}
\hline Production form & $\begin{array}{l}\text { static banner, active banner, two-way } \\
\text { banner }\end{array}$ \\
\hline Posting method & $\begin{array}{l}\text { fixed-type banner, key word-type banner, } \\
\text { rotation-type banner, scrolling-type } \\
\text { banner }\end{array}$ \\
\hline $\begin{array}{l}\text { Expression } \\
\text { method }\end{array}$ & $\begin{array}{l}\text { button-type banner, hot corner-type } \\
\text { banner, billboard-type banner, rich media- } \\
\text { type banner }\end{array}$ \\
\hline $\begin{array}{l}\text { Advertisement } \\
\text { scope }\end{array}$ & expansion banner, roll paper banner \\
\hline
\end{tabular}

Ho-seon Lee(2009) classified banners by the ways they are generated. As shown in Table 2, he divided them into four types: expression method, technology method, position method, figure method [7].

Table 2. Classification of banner advertisements depending on generation types

\begin{tabular}{c|l}
\hline $\begin{array}{c}\text { Expression } \\
\text { method }\end{array}$ & $\begin{array}{l}\text { button advertisement, prepaid placement of } \\
\text { Excite, rotation banner type, billboard type, } \\
\text { offline advertisement, PointCast }\end{array}$ \\
\hline $\begin{array}{c}\text { Technology } \\
\text { method }\end{array}$ & $\begin{array}{l}\text { Java-using banner, static banner, artificial } \\
\text { intelligence-type banner, interactive banner, } \\
\text { key word banner, shockwave banner, active } \\
\text { X banner, GIF banner }\end{array}$ \\
\hline Position method & $\begin{array}{l}\text { scroll banner, text banner, left menu button } \\
\text { banner, box banner, middle banner }\end{array}$ \\
\hline Figure method & CASIE \& IAB standard banner \\
\hline
\end{tabular}

Ji-eun Lee and Ji-hyeon $\operatorname{Kim}(2003)$ classified banner advertisements depending on when they appeared. As shown in Table 3, they divided them depending on objective, form, production technique, headline, and expression method [8].

Table 3. Classification of banner advertisements depending on the time order of their having been developed

\begin{tabular}{c|l}
\hline Objective & $\begin{array}{l}\text { campaign, product sale, event, prize, image } \\
\text { publicity, information provision }\end{array}$ \\
\hline Type & fixed type, animation type, interactive type \\
\hline $\begin{array}{c}\text { Production } \\
\text { technique }\end{array}$ & $\begin{array}{l}\text { GIF banner, Java banner, shockwave } \\
\text { banner, streaming banner }\end{array}$ \\
\hline Headline & $\begin{array}{l}\text { convenience type, information type, } \\
\text { stimulus type, question type, order type }\end{array}$ \\
\hline
\end{tabular}

\begin{tabular}{l|l}
\hline Expression type & $\begin{array}{l}\text { benefit appeal type, action demanding type, } \\
\text { emotion appeal type, humor appeal type, } \\
\text { color emphasis type, sex appeal type, } \\
\text { parody type, interactive type, new } \\
\text { technology type }\end{array}$ \\
\hline
\end{tabular}

Previous researches classified banner advertisements depending on exposed types, generation types, the time order of theirs have been developed. But, it is difficult to find classification depending on characteristics of specific products. Thus, if Internet banner advertisements considering the characteristics of high involvement-think group automobile are developed, they will make it possible to efficiently communicate with consumers, and stimulate consumers' procurement of the product. That is, it is necessary to do research on banner advertisement types considering procurement actions of consumers and product characteristics, and develop suitable banner advertisements.

\subsection{Visual expression of banner advertisements}

Visual expression of banner advertisements affects procurement decision of consumers. In his paper, "Influence of Expression Elements of Internet Banner Advertisements on Advertisement Attitude," Seung-whan Park, Chul-jae Choi(2009) proved that visual expression has effect on advertisement attitude and procurement intension [9]. Yeonjeong $\operatorname{Kim}(2000)$ also emphasized that in banner advertisement selection of proper media and visual expression of banner product are more important than other factors [10]. Previous researches on visual expressions which play very important role in Internet banner advertisement are as follows. Aran Kim(2003), considering that banner advertisement is posted in limited space called web page, classified banner advertisements by size, form, color, condition, layout, and typography [11]. Ho-seon Lee(2009), considering figurative elements that can attract attention of users, visual expressions into typography, color, form, and illustration, etc. [12]. On the other hand, Jeong-eun Lee(2005) argued that, in Internet banner advertisement design, visual and typography, etc. should be arranged clearly to make information understood quickly and clearly, and that the message intended to give should be clear to achieve effective communication, and classified visual expressions into position, color, image, and video [13]

Recently, Internet banner advertisement is evolving into sympathizing type, and the research on visual expression should go beyond color and layout, and consider movement and changing forms, etc [14]. Especially, as mentioned before, since Internet banner advertisement needs to make consumers understand the characteristics of the product, it is necessary to do research on visual expression method considering characteristics of products.

\section{AUTOMOBILE INTERNET BANNER ADVERTISEMENT TYPES AND SUGGESTION OF VISUAL EXPRESSION}


Examination of existing researches revealed that it is difficult to classify Internet banner advertisement types and visual expression methods. This study, for more efficient communication with consumers, suggests automobile Internet banner advertisement types and visual expression methods as follows. Fully considering the characteristics of automobile products such as FCB Grid model high involvement-think, and its evolvement into sympathetic type, this study suggested a banner advertisement type and visual expression method suitable for automobile banner advertisement, and also have experts in the field do face validity test. Automobile internet banner advertisements this study suggests are classified into four types as shown in Table 4: production form designed to attract consumers' attention; production purpose depending on the purpose of sending the message to consumers; expression types stimulating emotion of consumers; advertisement scope attracting consumers. More specifically, production form was classified into fixed banner, two way banner, and artificial intelligence banner; Production purpose was divided into event, image publicity and information provision; Expression type was sorted into emotion appeal type, interactive type, new technology type, and impact type; advertisement scope was differentiated into non-expansion, simple expansion, and multiexpansion.

Table 4. Suggestion of automobile internet banner advertisements types

\begin{tabular}{c|c|l}
\hline \multirow{4}{*}{$\begin{array}{c}\text { Types of } \\
\text { banner } \\
\text { advertisements }\end{array}$} & $\begin{array}{c}\text { Production } \\
\text { form }\end{array}$ & $\begin{array}{l}\text { fixed banner, two way } \\
\text { banner, artificial } \\
\text { intelligence banner }\end{array}$ \\
\cline { 2 - 3 } & $\begin{array}{c}\text { Expression } \\
\text { type }\end{array}$ & $\begin{array}{l}\text { emotion appeal type, } \\
\text { interactive type, new } \\
\text { technology type, impact } \\
\text { type }\end{array}$ \\
\cline { 2 - 3 } & Advermationage publicity, \\
& Advertisement & $\begin{array}{l}\text { non-expansion, simple } \\
\text { expansion, multi-expansion }\end{array}$ \\
\hline
\end{tabular}

Visual expression of automobile Internet banner advertisement was divided, as shown in Table 5, into movement form depending on mouse use behavior; image which has strong impact or implied message; changing forms of banner advertisement over time; moving form asking whether adjustment depending on the willingness of consumers is possible or not. More specifically, movement form is divided into mouse click, mouse over, mouse drag; Image is into photo, illustration, and composition; changing form is divided into simple form, complex form, and deviating form and moving form is into one-way form and adjustable one.

Table 5. Visual expression of automobile Internet banner advertisement

\begin{tabular}{c|c|l}
\hline $\begin{array}{c}\text { Visual } \\
\text { expression of }\end{array}$ & $\begin{array}{c}\text { Movement } \\
\text { form }\end{array}$ & $\begin{array}{l}\text { mouse click, mouse over, } \\
\text { mouse drag }\end{array}$ \\
\cline { 1 - 3 }
\end{tabular}

\begin{tabular}{c|c|l}
\hline $\begin{array}{c}\text { automobile } \\
\text { Internet } \\
\text { banner } \\
\text { advertisement }\end{array}$ & Image & $\begin{array}{l}\text { photo, illustration, } \\
\text { composition }\end{array}$ \\
\cline { 2 - 3 } & Changing form & $\begin{array}{l}\text { simple form, complex } \\
\text { form, deviating form }\end{array}$ \\
\cline { 2 - 3 } & Moving form & $\begin{array}{l}\text { one-way form, adjustable } \\
\text { one }\end{array}$ \\
\hline
\end{tabular}

\section{CASE ANALYSIS AND FINDINGS}

\subsection{Analysis overview}

Case analysis was done by the following procedure. First, top ten automobile banner advertisements were selected from related sites. 8 domestic and foreign automobile brands which are the most popular among users were selected as shown in Fig. 1. In selecting banners, this study took care that forms and expression methods of them were not overlapped. And, among the banner advertisements of the same brand automobile, what looks monotonous one was excluded, and what is creative in expression method was chosen. For case analysis, 100 students majoring in design were given a special space where they could watch banner advertisements. To secure reliable results, the data for only 93 students were used, excluding those of other students who did not fill out the form sincerely.

\begin{tabular}{c|c|c|c}
\hline Hyundai & BMW & GM & Honda \\
\hline Lexus & Peugeot & Volkswagen & Mercedes-Benz \\
\hline & & & \\
\hline & & & \\
\hline
\end{tabular}

Fig. 1. Automobile internet banner advertisement

\subsection{Findings of the analysis of automobile banner advertisement types}

Table 6 shows the findings of the analysis of automobile Internet banner advertisement types. Among the production forms, artificial intelligence banners took up 50\% of them, followed by fixed banner (37.5\%) and two-way banner (12.5\%). Artificial intelligence banner is equipped with artificial intelligence, and, when the user shakes the mouse on the banner, the image changes into another image or disappears. Such a special technique can make the user immerse himself or herself in it, so it is used widely by those companies. Among the choices of the production purposes, $75 \%$ of banners were related with image publicity, and remaining $12.5 \%$ of banners were related with event and information provision. It seems to reflect the reality that automobile companies consider banners advertising brand images as more important than those on event or information provision. Among different expression types, $37.5 \%$ of them were impact, followed by emotional appeal 
(25\%), and interactive and new technology (12.5\%). Compared with other items, various expression types were found to be used rather equally. Among the types of advertisement scope, multi-expansion took up 50\%, non-expansion did $37.5 \%$, and simple expansion did $12.5 \%$, which can be understood that those companies prefer non-expansion to simple expansion, and multi-expansion which means variety to non-expansion.

Table 6. Analysis result of automobile internet banner advertisement

\begin{tabular}{|c|c|c|c|c|c|}
\hline \multirow{2}{*}{$\begin{array}{l}\text { Production } \\
\text { form } \\
\text { Production } \\
\text { purpose }\end{array}$} & $\begin{array}{c}\text { fixed } \\
\text { banner }\end{array}$ & \multicolumn{2}{|c|}{ two way banner } & \multicolumn{2}{|c|}{$\begin{array}{c}\text { artificial } \\
\text { intelligence } \\
\text { banner }\end{array}$} \\
\hline & $37.5 \%$ & \multicolumn{2}{|c|}{$12.5 \%$} & \multicolumn{2}{|r|}{$50 \%$} \\
\hline \multirow{2}{*}{$\begin{array}{l}\text { Expression } \\
\text { type }\end{array}$} & event & \multicolumn{2}{|c|}{ image publicity } & \multicolumn{2}{|c|}{$\begin{array}{c}\text { information } \\
\text { provision }\end{array}$} \\
\hline & $12.5 \%$ & \multicolumn{2}{|c|}{$75 \%$} & \multicolumn{2}{|c|}{$12.5 \%$} \\
\hline \multirow{2}{*}{$\begin{array}{l}\text { Production } \\
\text { form } \\
\text { Production } \\
\text { purpose }\end{array}$} & $\begin{array}{l}\text { emotion } \\
\text { appeal } \\
\text { type }\end{array}$ & $\begin{array}{l}\text { interactive } \\
\text { type }\end{array}$ & \multicolumn{2}{|c|}{$\begin{array}{c}\text { new } \\
\text { technology } \\
\text { type }\end{array}$} & $\begin{array}{c}\text { impact } \\
\text { type }\end{array}$ \\
\hline & $25 \%$ & $12.5 \%$ & $25 \%$ & & $37.5 \%$ \\
\hline \multirow{2}{*}{$\begin{array}{c}\text { Expression } \\
\text { type }\end{array}$} & $\begin{array}{c}\text { non- } \\
\text { expansion }\end{array}$ & \multicolumn{2}{|c|}{ simple expansion } & \multicolumn{2}{|c|}{$\begin{array}{c}\text { multi- } \\
\text { expansion }\end{array}$} \\
\hline & $37.5 \%$ & \multicolumn{2}{|c|}{$12.5 \%$} & & $50 \%$ \\
\hline
\end{tabular}

4.3. Findings of the analysis of visual expression in automobile internet banner advertisements

Table 7 shows the findings of the analysis of visual expression in automobile Internet banner advertisements. In movement types, the overwhelming majority of them $(62.5 \%)$ was the mouse drag type, and $37.5 \%$ were the mouse click type. There was no mouse over type. Among the image types, 50\% of them were illustration, and photos and compositions were $25 \%$ respectively. Those companies seem to favor illustration technique where one can use various visual expressions and a wide range of graphic treatments. As changing forms, simple form and deviating form equally took up $37.5 \%$, larger than complex form (25\%). Such results seem to show that consumers favor changing form with clear purpose rather than what changes in complex ways. In moving forms, $62.5 \%$ were adjustable ones, and one-way things were $37.5 \%$. Consumers favor those banners they can adjust.

Table 7. Analysis result of Visual expression for automobile internet banner advertisement

\begin{tabular}{c|c|c|c}
\hline \multirow{2}{*}{$\begin{array}{c}\text { Movement } \\
\text { form }\end{array}$} & mouse click & mouse over & mouse drag \\
\cline { 2 - 4 } & $37.5 \%$ & $0 \%$ & $62.5 \%$ \\
\hline \multirow{2}{*}{ Image } & photo & illustration & composition \\
\cline { 2 - 4 } & $25 \%$ & $50 \%$ & $25 \%$ \\
\hline
\end{tabular}

\begin{tabular}{|c|c|c|c|}
\hline \multirow{2}{*}{$\begin{array}{l}\text { Changing } \\
\text { form }\end{array}$} & simple form & $\begin{array}{l}\text { complex } \\
\text { form }\end{array}$ & $\begin{array}{l}\text { deviating } \\
\text { form }\end{array}$ \\
\hline & $37.5 \%$ & $25 \%$ & $37.5 \%$ \\
\hline \multirow{2}{*}{$\begin{array}{l}\text { Moving } \\
\text { form }\end{array}$} & one-way form & \multicolumn{2}{|c|}{ adjustable one } \\
\hline & $37.5 \%$ & \multicolumn{2}{|c|}{$62.5 \%$} \\
\hline
\end{tabular}

\section{CONCLUSION}

This study was to suggest an efficient communication method of automobile Internet banner advertisements. It started with the examination of findings of previous researches. Then, this study summarily suggested what is not sufficient in those researches. What was suggested considered sufficiently the evolution of automobile Internet banner advertisements into sympathetic one, and the characteristics of FCB Grid model high involvement-think group of automobiles.

This study divided automobile Internet banner advertisement types into production form, posting method, expression method, and advertisement scope, and analyzed cases. Visual expression of automobile Internet banner advertisements were classified into 4 types: movement type, image, changing form, moving form, and cases were analyzed using the classification. First of all, the findings of banner advertisement type analysis showed that artificial intelligence banner, image publicity, impact type, and multi-expansion were found to be high. Such results were highly correspondent with the elements used in automobile banner advertisement type suggested considering the characteristics of FCB Grid model high involvement-think group of automobile. In analytical results of visual expression showed that mouse drag, illustration, adjustable type was high. The fact that mouse drag of movement form and the adjustable of moving form were high in case analysis demonstration that the suggested method is meaningful.

Such findings seem to show that Internet banner advertisement will play a more vivid role in the rapidly changing online advertisement market. And, it is expected that Internet banner advertisement produced on the basis of understanding of the trend of the market and characteristics of the product will play the role of efficient communication more highly.

\section{REFERENCES}

[1] B. S. Seo, Advertising Planning, Nanam, 1990, p. 101.

[2] H. C. Kim, Captivation \& Creative, Dasan Books, 2006, p. 27.

[3] S. J. Park, "An Analysis on Humor Expression in Internet Banner Advertising," The Korea Contents Association, vol. 11, no. 2, 2011, p. 172.

[4] S. J. Park, A Study on Emotional Expression Strategy in Internet Banner Advertising, Graduate School of WonKwang University, 2011, pp. 68-70. 
[5] E. G. Han, An Advertisement Theory of $I M C$, Communication Books, 2001, p. 166.

[6] Y. K. Ko and I. S. Seo, "The Study on Pattern Preferences of Banner Advertisement according to the Type of Business," The Korean Society of Design Culture, vol. 17 no. 1, 2011, p. 18 .

[7] H. S. Lee, "A Study of Design Type and Expression at Internet Banner Advertisement," Korean Society of Design Culture, vol. 7, no. 2, 2009, pp. 136-140.

[8] J. E. Lee and J. H. Kim, "Effective Application of Timing for Motion typography in Banner Advertising on Internet", Korea Society of Basic Design \& Art, vol. 4, no. 1, 2003, p. 170.

[9] S. W. Park and C. J. Choi, "Effects the Expression Components on Attitude Toward Advertising in the Internet Banner Advertisements", Society of Korea Design Trend, vol 23, no. 2, 2009, p. 45.

[10] Y. J. Kim, A Study on the Effective Design Expression in the Internet Advertising, Graduate School, Taegu University, 2000, p. 17.

[11] A. R. Kim, A Study on the Web Banner Advertisement, Graduate School of Chungang University, 2003, pp. 30-50.

[12] H. S. Lee, "A Study of Design Type and Expression at Internet Banner Advertisement", Korean Society of Design Culture, vol. 7, no. 2, 2009, p. 141.

[13] J. E. Lee, A Study on Measuring Effectiveness of Webbased Advertisement Banners and Analysis of Their Design, The Graduate School of Yonsei University, 2005, pp. 34-39.

[14] S. J. Park, "A Study on Expression in Car Advertisement Using Banners in Internet", The $3^{\text {rd }}$ International Conference on Convergence Technology(ICCT) 2013, vol. 2, no. 1, 2013, pp. 1631-1632.

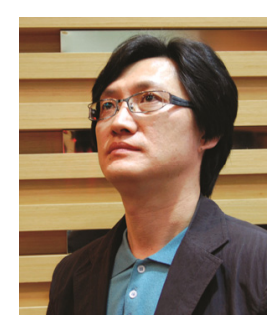

\section{Sang-Jin Park}

He received his B.A. degree in Industrial Design from chonbuk National University, Korea in 1994, and M.A. in Multimedia Design from DeMontfort University, England in 1998, and also received Ph.D. degree in Visual Design from Wonkwang University, Korea in 2012. Since then, he has been with Konyang University, Korea as a professor. His main research interests are Digital Contents, Interface Design, Motion graphic. 